\title{
Relationship of Self-efficacy with Mindfulness and Empathy in Red Crescent Society Volunteers in Saveh, Iran
}

\author{
Mojtaba Vahedian $^{1}\left(\mathbb{D}\right.$, Vajihe Salem $^{2}(\mathbb{D}$
}

Date of submission: 21 Sep. 2019 Date of acceptance: 20 Apr. 2020

\begin{abstract}
INTRODUCTION: It is an indisputable fact that people who live in societies will always need each other. In this regard, the members of a society should try to decrease the problems and difficulties of the community by participating in voluntary services. The present study aimed to investigate the relationship of self-efficacy with mindfulness and empathy in volunteers of the Red Crescent society in Saveh, Iran.

METHODS: This practical study was conducted based on a descriptive-survey method. The population included 100 experts and key members of the Sistan and Baluchistan Crisis Management Coordination Council. In total 80 cases were selected using Cochran's formula and purposive (snowball) sampling method. The data were collected through a 46-item researchermade questionnaire. The face and content validity of the questionnaire was confirmed by experts, and the reliability of the questionnaire was estimated at 0.94 using Cronbach's alpha coefficient, which indicated acceptable reliability of this scale. The data were analyzed in SPSS software (version 22) through multiple regression to evaluate the research hypotheses.

FINDINGS: Based on the results, mindfulness $(\mathrm{P}<0.05, \mathrm{r}=0.468)$ and expressive empathy $(\mathrm{P}<0.01, \mathrm{r}=0.207)$ had a positive and significant relationship with self-efficacy; however, empathy did not have a relationship with other variables. Moreover, out of the subscales of empathy, empathy for others $(\mathrm{P}<0.05, \mathrm{r}=-0.138)$ and control $(\mathrm{P}<0.01, \mathrm{r}=-0.210)$ had a negative relationship with self-efficacy. The mindfulness variable was significant in the prediction of selfefficacy $(\mathrm{F}=25.353)$ which explains about $21.8 \%$ of the variance of the criterion variable. Moreover, the component of emotional stability was significant in the prediction of self-efficacy $(\mathrm{F}=16.379)$ which explains about $5 \%$ of the variance of the criterion variable. Therefore, with a coefficient of determination of $51.7 \%$ the changes in self-efficacy are explained by mindfulness and the component of emotional stability.

CONCLUSION: According to the findings, the variables of mindfulness and the component of emotional stability can significantly predict self-efficacy. Furthermore, mindfulness with a beta of 0.467 had the greatest effect on self-efficacy.
\end{abstract}

Original Article

Keywords: Empathy; Mindfulness; Red Crescent Society Volunteers; Self-efficacy.

How to cite this article: Vahedian M, Salem V. Relationship of Self-efficacy with Mindfulness and Empathy in Red Crescent Society Volunteers in Saveh, Iran. Sci J Rescue Relief 2019; 11(4): 260-66.

\section{Introduction}

I $\mathrm{n}$ the Red Crescent Society, voluntary service is a means used by an individual or group to realize one of the fundamental principles of the Red Cross and Red Crescent Society, namely "voluntary service". In fact, voluntary service is a voluntary and benevolent act that expresses one's desire to be in solidarity with other human beings. These services make the receivers know that they are not alone and will always belong to a group or

1-Faculty Member, Department of Psychology and Educational Sciences, Payame Noor University, Tehran, Iran

2-B.Sc, Psychology, Payame Noor University, Tehran, Iran

Correspondence to: Mojtaba Vahedian, Email: mojtabavahedian@gmail.com 
community (1). Therefore, the people who offer such services must have a set of traits and behaviors, the most important of which are mindfulness, empathy, and self-efficacy. Selfefficacy is one of the main components of social cognitive theories and refers to the individual's beliefs and judgments about his/her abilities to perform duties and responsibilities (2).

The structure of self-efficacy is of special importance in educational environments since according to Bandura; such environments are suitable for growth and formation of self-efficacy (3). Fulfillment of duties, high-level performance commensurate with one's capability, problemsolving skills, proper use of analytical thinking, acceptance of failure, selection of challenging tasks, commitment and perseverance in fulfilling it, and self-mastery when the withdrawal is necessary are among the characteristics of a person with self-efficacy (4).

According to Bandura, self-efficacy regulates human actions through cognitive, motivational, emotional, and decision-making processes (5). People who believe they can control potential threats and pressures, do not allow disturbing cognitions to influence them and make them lose control. On the other hand, lack of self-efficacy in the face of potential threats and stressful situations leads to stress and anxiety arousal (6).

Social, educational, emotional, and creative self-efficacy are among the aspects of self-efficacy that have attracted the attention of researchers in recent years. Educational self-efficacy, which refers to one's sense of empowerment in learning (9) affects educational outcomes by increasing motivation and facilitating the efficient use of achieved knowledge and skills (7). Social selfefficacy is one's assessment of his/her own ability to establish and maintain interpersonal relationships and face social challenges, which includes social courage, desirable social relations, exchange of friendly feedback, group participation, or social activity $(8,9)$.

Emotional self-efficacy refers to one's belief in their ability to control and manage emotions. Creative self-efficacy refers to one's belief that $\mathrm{s} / \mathrm{h}$ has the ability to produce creative outcomes. It is a form of self-assessment that influences decisions about the amount of effort and the level of commitment when faced with creative challenges (9). Mindfulness is an unintentional contemplation of current events. It is defined as a receptive, judgment-free consciousness of what is happening at the moment (10).

Mindfulness is derived from cognitivebehavioral therapies and is one of the important elements of the third wave of psychological therapy models. It is a kind of focused awareness that is conscious and directed and can raise the level of awareness regarding all mental events or present states (11). Mindfulness refers to conscious, diligent, and controlled processing which stands in opposition to negligence (12). People with mindfulness perceive internal and external realities freely and without distortion and also have a great ability to face a wide range of thoughts, emotions, and experiences (both pleasant and unpleasant) (10).

According to Byron (2006), useful guides for adaptation to mindfulness in order to create and maintain awareness include lack of judgment and evaluation, patience, initiative mind, lack of engagement, acceptance, and liberation. Mindfulness is the decisive attention to the matters of the present time that we have perceived differently until now (13). Gellman (2005) defines mindfulness as awareness of the present experiences, acceptance, awareness, and consciousness of reality, confrontation with the nature of experiences, and observation of things as if they are seen for the first time (14).

Empathy is considered as the ability to understand and convey an understanding of the thoughts and feelings of others. Empathy enables people to perceive others' experiences as if they have experienced them (15). It is one of the most important emotional abilities and starts manifesting itself from early childhood (16). Empathy is one of the components of social cognition that guides interaction in the right direction. It is defined as the ability to understand others, experience their feelings, and respond appropriately to the situation (17). Empathy consists of two main components, namely the cognitive and emotional components. Cognitive empathy is the ability to understand the emotions of others and the emotional component of the individual's emotional response to an emotional stimulus (15).

It should be noted that self-efficacy can positively affect the performance of tasks that are related to helping and assisting people in times of crisis and problem-solving. This issue has been confirmed by the results of many studies in various 
fields. For instance, Wampold and Watson (2001) found that one of the essential skills for the successful achievement of self-efficacy in counseling is the ability to focus on the present and empathize with the clients. Moreover, based on the results of the above-mentioned study, one of the characteristics of self-efficacy in the counseling session is the consultant's ability to pay effective attention and guide his/her cognition (18).

Sanmartín and Carbonell (2011) in their research found that there is a positive relationship between empathy, self-efficacy, responsibility, socialization, and prosocial behaviors (19). Furthermore, based on the results of the study performed by Goroshit and Hen (2016), selfefficacy has an important effect on teachers' empathy (20). RazmiSoha and RazmiSoha (2015) in their study showed that the level of empathy and self-efficacy among Red Crescent staff is higher than ordinary people (21). Besides, regarding the relationship between mindfulness and self-efficacy, Riahi et al. (2016) found that teaching mindfulness to mothers increases selfefficacy in their children (22).

Mehdizadeh Azdin et al. (2017) in their study confirmed the effectiveness of mindfulness-based cognitive therapy on increasing social self-efficacy (23). Moreover, the findings of the research performed by Mirdrikund et al. (2015) showed that the implementation of an intervention with the aim of teaching metacognitive techniques has been effective in increasing self-efficacy (24). In addition, Luberto et al. (2014) found that coping self-efficacy indicates a person's confidence in his/her ability to cope effectively with difficult and threatening events, as a mediator in the relationship between mindfulness and emotional regulation (25).

Furthermore, Shah Moradi Tabatabai and Ansari Shahidi (2017) showed that mindfulness increases general self-efficacy (26). Greason and Cashwell (2009) also supported the hypothesis that mindfulness is a significant predictor of the variables of counseling self-efficiency and attention for empathy (27). In this regard, the present study aimed to investigate the relationship of selfefficacy with mindfulness and empathy in the Red Crescent society volunteers in Saveh, Iran.

\section{Methods}

The present research used the correlational method, which is the most common type of descriptive (non-experimental) research. Moreover, the statistical population of this study was all the volunteers of the Red Crescent Society of Saveh. The subjects were selected from among the volunteers participating in the first aid and introductory search and rescue courses in January 2019. In total, 93 samples were selected using the convenience sampling method. The inclusion criteria consisted of volunteer participation in the above-mentioned courses and willingness to cooperate.

\section{Research tools}

\section{A) Sherer General Self-efficacy Scale}

This scale has 17 items that are scored based on a five-point Likert scale ranging from strongly disagree to strongly agree. Items $1,3,8,9,13$, and 15 are scored from right to left and the rest of the items are scored in reverse (i.e., from left to right). Therefore, the maximum and minimum scores that can be obtained from this scale were 85 and 17 , respectively.

The reliability coefficient of this scale was calculated at 0.76 and 0.79 by Guttman split-half reliability and Cronbach's alpha coefficient, respectively (28). Moreover, Vaghari (2000) in his study obtained the reliability of self-efficacy at 0.85 by Cronbach's alpha. Furthermore, Najafi (2001) randomly selected 30 subjects from the participants of his study and performed the selfefficacy test on them. He estimated the reliability at 0.83 by both Cronbach's alpha and the Spearman-Brown formula. In another study carried out by Ganji and Farahani (2009), the reliability of this scale was calculated at 0.81 by Cronbach's alpha (29). In the present study, the obtained reliability was 0.7 by Cronbach's alpha.

\section{B) Freiburg Mindfulness Inventory-Short form}

This questionnaire has 17 items that are scored based on a 4-point Likert scale from 1 (rarely) to 4 (almost always). It should be noted that item number 13 was scored in reverse. The minimum and maximum scores that could be achieved in this questionnaire were 14 and 56, respectively. The short form of the Freiburg Mindfulness Inventory has acceptable and sufficient reliability and the obtained coefficients for Cronbach's alpha coefficient and ordinal theta were 0.92 and 0.93 , respectively. Furthermore, the test-retestreliability coefficient was 0.83 for a four-week interval (30). In the present study, the reliability 
was obtained at 0.75 .

\section{C) The Mehrabian and Epstein Empathy Scale}

This scale was developed by Mehrabian and Epstein (1972) and has 33 items, 17 of which are positive and the other 16 are reverse. Each item has 5 options, namely strongly agree, agree, neutral, disagree, and strongly disagree, that are scored from 5 to 1 , respectively. This questionnaire includes subscales of relational empathy, expressive empathy, cooperative empathy, to be moved by others' emotional experiences, emotional stability, empathy with others, and control. Based on a study that used this scale on 101 men and 101 women, its reliability coefficient was reported to be 0.84 (31). In a study performed by Zarshaghaei et al. (2010), the reliability coefficient of the scale was calculated at $0.559(\mathrm{P}<0.001)(32)$. Moreover, in the present study, the obtained reliability coefficient was 0.5 .

\section{Findings}

Pearson correlation coefficients were used to investigate the relationship between the variables and the required data are summarized in Table 1. As can be seen, self-efficacy was the predictable variable, while mindfulness and empathy with its components were the predictive variables. As can be seen in Table 1 , the mean value of the self- efficacy of the subjects was 57.61 \pm 9.6 . Moreover, the mean value of mindfulness of the subjects was $17.37 \pm 67.4$. Among the empathy subscales of the subjects, the relational empathy and control subscales obtained the highest (96.21) and lowest (6.6) mean values, respectively. Moreover, the mean value of the total empathy of the subjects was $98.107 \pm 81.7$.

Table 1 also shows that mindfulness $(\mathrm{P}<0.05$, $r=0.467)$ had a positive and significant relationship with self-efficacy; accordingly, the increase of mindfulness, leads to an increase in self-efficacy. Furthermore, control $(\mathrm{P}<0.01, \mathrm{r}=-$ 0.210 ) had a negative and significant relationship with self-efficacy; accordingly, the increase of self-efficacy led to a decrease in the level of control $(\mathrm{P}<0.01, \mathrm{r}=0.207)$.

Mindfulness had a positive and significant relationship with expressive empathy $(\mathrm{P}<0.01$, $\mathrm{r}=0.207)$ and a negative and significant relationship with empathy for others $(\mathrm{P}<0.05, \mathrm{r}=-$ 0.317 ). Self-efficacy and mindfulness had no significant relationship with empathy. Stepwise regression and regression coefficients were used to determine which of the variables was predictive and which one was the most important variable in prediction. The results of the regression analysis are summarized in Table 2 .

In Table 2 of Model 1, the mindfulness variable is significant in the prediction of self-

Table 1. Mean, standard deviation, and correlation coefficients of mindfulness, empathy, and self-efficacy

\begin{tabular}{|c|c|c|c|c|c|c|c|c|c|c|c|c|}
\hline \multirow[b]{2}{*}{ Variables } & \multicolumn{12}{|c|}{ Subjects } \\
\hline & Mean & $\begin{array}{l}\text { Standard } \\
\text { deviation }\end{array}$ & 1 & 2 & 3 & 4 & 5 & 6 & 7 & 8 & 9 & 10 \\
\hline Self-efficacy & 57.61 & 9.6 & 1 & & & & & & & & & \\
\hline Mindfulness & 17.37 & 67.4 & $0.468 * *$ & 1 & & & & & & & & \\
\hline Empathy & 98.107 & 81.7 & -0.156 & -0.044 & 1 & & & & & & & \\
\hline $\begin{array}{l}\text { Relational } \\
\text { empathy }\end{array}$ & 96.21 & 92.2 & -0.112 & -0.151 & $0.489 * *$ & 1 & & & & & & \\
\hline $\begin{array}{l}\text { Expressive } \\
\text { empathy }\end{array}$ & 05.15 & 36.2 & 0.152 & $0.207 *$ & $0.370 * *$ & $0 . \overline{-} 21 *$ & 1 & & & & & \\
\hline $\begin{array}{l}\text { Cooperative } \\
\text { empathy }\end{array}$ & 06.20 & 54.2 & 0.135 & 0.113 & $0.456 * *$ & 0.017 & $0.304 * *$ & 1 & & & & \\
\hline $\begin{array}{c}\text { Moved by others' } \\
\text { emotional } \\
\text { experience }\end{array}$ & 55.18 & 98.2 & -0.175 & 0.052 & $0.604 * *$ & 0.204 & 0.068 & $0.291 * *$ & 1 & & & \\
\hline $\begin{array}{l}\text { Emotional } \\
\text { stability }\end{array}$ & 19.12 & 97.1 & -0.191 & 0.063 & $0.448 * *$ & 0.136 & -0.076 & 0.051 & $0.287 * *$ & 1 & & \\
\hline $\begin{array}{c}\text { Empathy with } \\
\text { others }\end{array}$ & 12.14 & 34.2 & -0.134 & $-0.318 * *$ & $0.449 * *$ & $0.212 *$ & 0.075 & -0.047 & -0.075 & 0.088 & 1 & \\
\hline Control & 6.6 & 45.1 & $-0.220 *$ & -0.109 & $0.401 * *$ & $0.222 *$ & -0.025 & -0.102 & $0.232 *$ & 0.106 & 0.204 & 1 \\
\hline
\end{tabular}


Table 2. Analysis of variance of the regression model of predictors of mindfulness and empathy (emotional stability component) and the criterion variable of self-efficacy

\begin{tabular}{cccccccc} 
Source of changes & Sum of squares & Degree of freedom & Mean square & $\mathbf{F}$ & $\mathbf{P}$ & $\mathbf{R}^{\mathbf{R}^{2}}$ \\
\hline Regression & 956.848 & 1 & 956.848 & 25.353 & 0.000 & 0.467 & 0.218 \\
Remainder & 3434.399 & 91 & 37.741 & & & & \\
Total & 4391.248 & 92 & 585.849 & 16.379 & 0.000 & 0.517 & 0.267 \\
Regression & 1171.788 & 2 & 35.772 & & & & \\
Remainder & 3219.460 & 90 & & & & \\
Total & 4391.248 & 92 & & &
\end{tabular}

Table 3. Regression coefficients

\begin{tabular}{c|ccccc}
\multirow{2}{*}{ Regression model } & \multicolumn{2}{|c}{ Unstandardized coefficients } & Standardized coefficients & t-value & P \\
& Regression coefficient B & Standard error & $\boldsymbol{\beta}$ & 7.003 & 0.000 \\
y-intercept & 35.937 & 5.131 & 0.467 & 5.035 & 0.000 \\
Mindfulness & 0.690 & 0.137 & & 7.288 & 0.000 \\
y-intercept & 44.602 & 6.120 & 0.481 & 5.316 & 0.000 \\
Mindfulness & 0.710 & 0.134 & -0.222 & -2.451 & 0.000 \\
\hline Emotional stability & -0.774 & 0.316 & & & \\
\hline
\end{tabular}

efficacy $(\mathrm{F}=25.353)$, which explains about $21.8 \%$ of the variance of the criterion variable. Moreover, the emotional stability component is also significant in the prediction of self-efficacy $(\mathrm{F}=16.379)$ and explains about $5 \%$ of the variance of the criterion variable. Therefore, based on the coefficient of determination, it can be stated that $51.7 \%$ of the changes in self-efficacy are due to mindfulness and the component of emotional stability.

According to Table 3, the results of the stepwise regression analysis regarding the research hypothesis indicated that the variable of mindfulness and the component of emotional stability can significantly predict mental wellbeing. Therefore, if the mindfulness predictor variable increases by one standard deviation, selfefficacy will increase by 0.48 standard deviation. Moreover, the contribution of the emotional stability component to the prediction of selfefficacy was negative which means that if emotional stability decreases by one standard deviation, self-efficacy will increase by 0.22 standard deviation. Furthermore, it was found that mindfulness with a beta of 0.467 had the most significant effect on the self-efficacy variable, while other components of empathy did not have a significant effect on self-efficacy.

\section{Discussion and Conclusion}

Based on the results of the correlation test, mindfulness had a positive and significant relationship with self-efficacy; however, empathy did not have a relationship with self-efficacy. Among the components of empathy, control had a negative and significant relationship with selfefficacy, while expressive empathy had a positive and significant relationship with it. Moreover, empathy with others had a negative and significant relationship with mindfulness. Furthermore, the results of stepwise regression also indicated that mindfulness predicts selfefficacy positively; accordingly, with the increase of self-awareness, self-efficacy also increases. However, the component of emotional stability predicts self-efficacy negatively.

Consistent with the results of the present study, those of research conducted by Riahi et al. (22), Mehdizadeh Azdin et al. (23), Shah Moradi Tabatabai, and Ansari Shahidi (26) indicated the effect of mindfulness training on self-efficacy. Moreover, Mirdrikvand et al. (2015) found that an intervention based on teaching metacognitive techniques can increase self-efficacy (24).

As previously discussed, the results of the studies carried out by Luberto et al. (25) and Greason and Cashwell (27) indicated the same relationship and confirm the results of the present study. Therefore, as it was found in the present study and several other studies, there is a significant relationship between mindfulness and self-efficacy.

According to the research performed by Ranjbar Noshahri, Hashemi, Asadi Majareh and Mohaddesi (2013), and Teymouri, Khakpour, and Momeni Mahmouyeh (2015) quoted in 
Mahdipour and Kurd (6), people with selfefficacy do not allow disturbing cognitions to affect them and do not lose their control. On the other hand, lack of self-efficacy in the face of potential threats and stressful situations leads to the experience of stress and anxiety arousal.

Behrad and Abdollahzadeh Jedi (33) in their study concluded that mindfulness training reduces self-efficacy in education by reducing psychological distress. Therefore, mindfulness is one of the effective predictors of self-efficacy and should be considered in any position. However, not much research has been performed on the second variable of empathy and the results of the few existing studies are inconsistent with those of the present study.

The studies carried out by Cortis, Scarti, and Pascal (19), Goroschit and Hen (20), Razmisoha and Razmisoha (21), and Greason and Cashwell (27) have indicated a positive relationship between empathy and self-efficacy, while only the component of emotional stability had a negative prediction. This is inconsistent with the results of the present study; therefore, it seems necessary to perform more extensive research on the variables of empathy and self-efficacy in order to find the relationship between these two variables.

The present research can help the Red Crescent Society to become aware of the performance of the volunteers and develop plans to strengthen self-efficacy and mindfulness of the volunteers who participate in their training courses. Empathy is also an important feature in times of crisis and more research should be performed on this variable as well. Since there is a need for trained and capable people to meet the needs of the society in times of trouble and volunteers play a significant role in such situations, more attention should be paid to these behavioral characteristics and traits in them.

\section{Acknowledgments}

The authors of the article would like to thank all those who contributed to this research.

\section{Conflict of Interests}

There is no conflict of interest regarding the publication of the study.

\section{References}

1. Training department of the Red Crescent Youth
Organization. Voluntary services (especially for teachers and students). Tehran: Iranian Red Crescent Society; 2004. [In Persian].

2. Kreitler S, Peleg D, Ehrenfeld M. Stress, selfefficacy and quality of life in cancer patients. Psycho Oncol 2007; 16(4): 329-41.

3. Bandura A, Rumsey M, Walker C, Harris J. Regulative function of perceived self-efficacy. New Jersey: Personnel Selection and Classification; 1994. P. 261-71.

4. Esmaeeli FN, Shafiabadi A, Ahghar G. Proportion of self-efficacy in the prediction of happiness. J Clin Psychol Andishe Raftar 2011; 5(9): 27-34. [In Persian].

5. Bagheri F, Hosniyeh Y. Hardiness, self-efficacy \& affective self-regulation styles amongst female high schoolers of Tehran. J Clin Psychol Andishe Raftar 2010; 4(14): 35-46. [In Persian].

6. Kord B. The relationship between mindfulness and perceived self-efficacy with subjective well-being among cancer patients in Tabriz hospitals. Iran J Nurs Res 2018; 13(1): 11-7. [In Persian].

7. Chenari S, Yousefi F. The adolescents' selfefficacy dimensions in different family types based on the contextual family process and content model. J Psychol Models Methods 2015; 5(18): 124. [In Persian].

8. Lv B, Zhou H, Liu C, Guo X, Zhang C, Liu Z, et al. The relationship between mother-child discrepancies in educational aspirations and children's academic achievement: the mediating role of children's academic self-efficacy. Child Youth Serv Rev 2018; 86: 296-301.

9. Bandura A, Pastorelli C, Barbaranelli C, Caprara GV. Self-efficacy pathways to childhood depression. J Personal Soc Psychol 1999; 76(2): 258.

10. Nejati V, Zabihzadeh A, Nikfarjam M. The relationship of mindfulness with sustained and selective attentional performance. Res Cogn Behav Sci 2013; 2(2): 31-42. [In Persian].

11. McCarney RW, Schulz J, Grey AR. Effectiveness of mindfulness-based therapies in reducing symptoms of depression: a meta-analysis. Eur $\mathbf{J}$ Psychother Counsel 2012; 14(3): 279-99.

12. Bishop SR, Lau M, Shapiro S, Carlson L, Anderson ND, Carmody J, et al. Mindfulness: a proposed operational definition. Clin Psychol Sci Pract 2004; 11(3): 230-41.

13. Golpour CR, Mohammad AZ. The efficacy of mindfulness based stress reduction on mindfulness and assertiveness of students with test anxiety. J Sch Psychol 2011; 1(3): 82-100. [In Persian].

14. Schure MB, Christopher J, Christopher S. Mindbody medicine and the art of self-care: teaching mindfulness to counseling students through yoga, meditation, and qigong. J Counsel Dev 2008; 86(1): 47-56. 
15. Taheri A, Soheili F, Pourshahriari M. Social intelligence and medical empathy in Iranian and English medical students: a comparative crosscultural study. Shenakht J Psychol Psychiatr 2017; 4(1): 38-50. [In Persian].

16. Vaziri S, Lotfi AA. The effect of empathy training in decreasing adolescents' aggression. Dev Psychol 2012; 8(30): 167-75. [In Persian].

17. Khanjani Z, Khani FH, Abad TH, Aliloo MM, Roudsari AB. Dimensional association between schizotypy and empathy: structural link of positive and negative schizotypy with cognitive and affective empathy. Modern Psychol Res 2012; 7(26): 17. [In Persian].

18. O'byrne K, Clark RE, Malakuti R. Expert and novice performance: Implications for clinical training. Educ Psychol Rev 1997; 9(4): 321-32.

19. Gutiérrez Sanmartín M, Escartí Carbonell A, Pascual Baños C. Relationships among empathy, prosocial behavior, aggressiveness, self-efficacy and pupils' personal and social responsibility. Psicothema 2011; 23(1): 13-9.

20. Goroshit M, Hen M. Teachers' empathy: can it be predicted by self-efficacy? Teachers Teach 2016; 22(7): 805-18.

21. Razmisoha Z, Razmisoha M. Comparison of empathy and self-efficacy in Red Crescent staff and ordinary people. Second National Conference and First International Conference on Modern Research in Humanities, Tehran, Iran; 2015. [In Persian].

22. Riahii M, Esmaeily M, Kazemian S. Effect of training mindfulness to mothers on improving parent-child relationship with subsequent selfefficacy in children. J Family Res 2016; 12(45): 27 52. [In Persian].

23. Mahdizadeh AS, Mousavi SA, Jalali M, Kakavand A. The effectiveness of mindfulness-based cognitive therapy on social self-efficacy and depression. Dev Psychol 2018; 14(55): 305-14. [In Persian].

24. Mirdrikvand F, Sabzian S, Geravand $H$. Effectiveness of metacognitive techniques training on girl students self-efficacy in high schools of Isfahan city. J Res Sch Virtual Learn 2015; 2(8): 7 16. [In Persian].

25. Luberto CM, Cotton S, McLeish AC, Mingione CJ, O'Bryan EM. Mindfulness skills and emotion regulation: The mediating role of coping selfefficacy. Mindfulness 2014; 5(4): 373-80.

26. Shahmoradi Tabatabai T, Ansari Shahidi M. The effect of mindfulness training on the self-efficacy of high school girls. International Conference on Psychopathology and Education, Tehran, Iran; 2017. [In Persian].

27. Greason PB, Cashwell CS. Mindfulness and counseling self-efficacy: the mediating role of attention and empathy. Counselor Educ Superv 2009; 49(1): 2-19.

28. Shamaeezadeh M, Abedi M. The effect of selfefficacy increased entrepreneurial career advice to students of Isfahan University. Knowl Res Appl Psychol 2005; 1(7): 29-38. [In Persian].

29. Cronbach's alpha. Iran Consultant. Available at: URL: http://www.iran-moshaver.ir/; 2019. [In Persian]

30. GhasemiJobaneh R, Arabzadeh M, JaliliNikoo S, MohammadAlipoor Z, Mohsenzadeh F. Survey the validity, and reliability of the Persian version of short form of Freiburg mindfulness inventory. J Rafsanjan Univ Med Sci 2015; 14(2): 137-50. [In Persian].

31. Mehrabian A, Epstein N. A measure of emotional empathy. J Personal 1972; 40: 525-43.

32. Zarshghaee M, Nori A, Oraizi H. Psychometric properties of the Persian version of the balanced emotional empathy scale. J Psychol Models Methods 2010; 1(1): 39-50. [In Persian].

33. Behrad H, Abdollahzadeh Jeddi A. Prediction of academic self-efficacy of the secondary school students in the city of Meshgin based on the mindfulness and negative emotions score. J N Adv Behav Sci 2017; 2(12): 1-13. [In Persian]. 